\title{
Behavioral Effects of Chronic Exposure to Trace Concentrations of Isoflurane in Mice
}

\section{Emad A. Abdelkareem, MD, Pharmacology Department, Faculty of Medicine, Alazhar University, Egypt}

\section{Background:}

Acute exposure to isoflurane is documented to cause cognitive and behavioral impairment in both animals and human studies. Occupational exposure to trace concentrations of isoflurane occurs in operating rooms, recovery rooms, dental operatories and veterinary facilities. The purpose of this experimental work is to determine if chronic exposure to trace concentrations of isoflurane can result in effects resembling those of acute exposure in anesthetic concentrations or not.

\section{Methods:}

56 male albino mice were divided into 4 groups (14 mice each). Control group (G1) received $3 \mathrm{~L} / \mathrm{min} 100 \% \mathrm{O}_{2} 8 \mathrm{~h}$ daily for 8 weeks, then exposed to behavioral study on Morris water maze to test spatial memory, T maze to test non-spatial memory, open field to test anxiety and exploratory behavior and rotarod to test motor learning and memory) immediately 8 weeks after exposure and after another 8 weeks in an ordinary environment. Isoflurane groups $(\mathrm{G} 2, \mathrm{G} 3$, and $\mathrm{G} 4)$, received $32 \mathrm{ppm}, 16 \mathrm{ppm}$ and $8 \mathrm{ppm}$ in $100 \% \mathrm{O}_{2} 8 \mathrm{~h}$ a daily for 8 weeks and then exposed to behavioral study as control group.
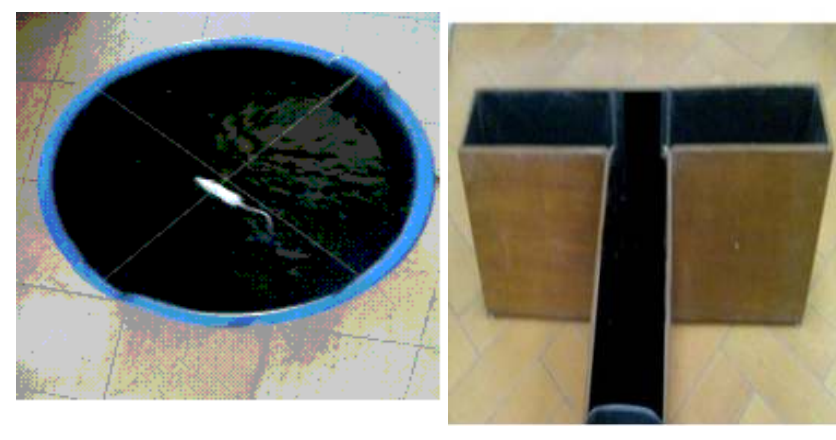

Morris Water Maze T maze

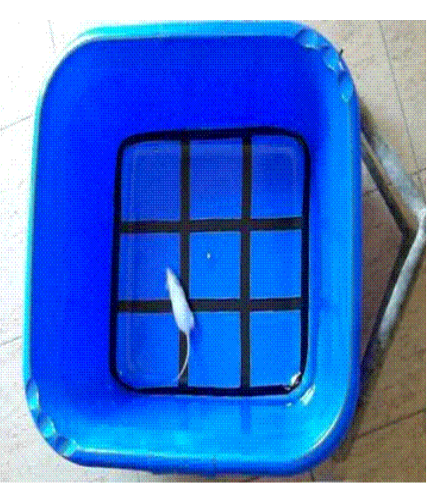

Open Field Arena

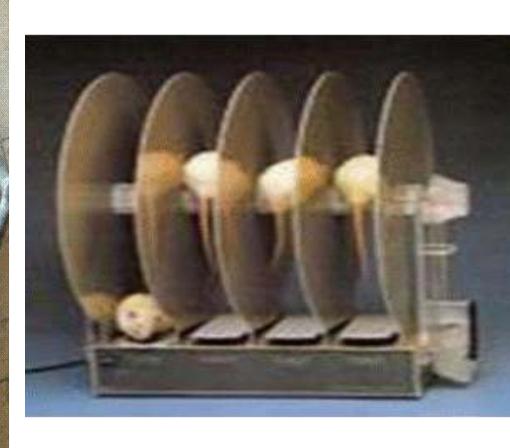

Rotarod
Results:

Chronic exposure to trace isoflurane resulted in long-term/reference memory impairment (Morris water maze) and impairment in non-spatial working memory ( $\mathrm{T}$ maze) in a dose dependant manner. While anxiety and exploratory activity (open field arena) did not affect also motor learning and coordination ( rotarod ) did not affect. These effects were the same after 8 weeks in an ordinary environment

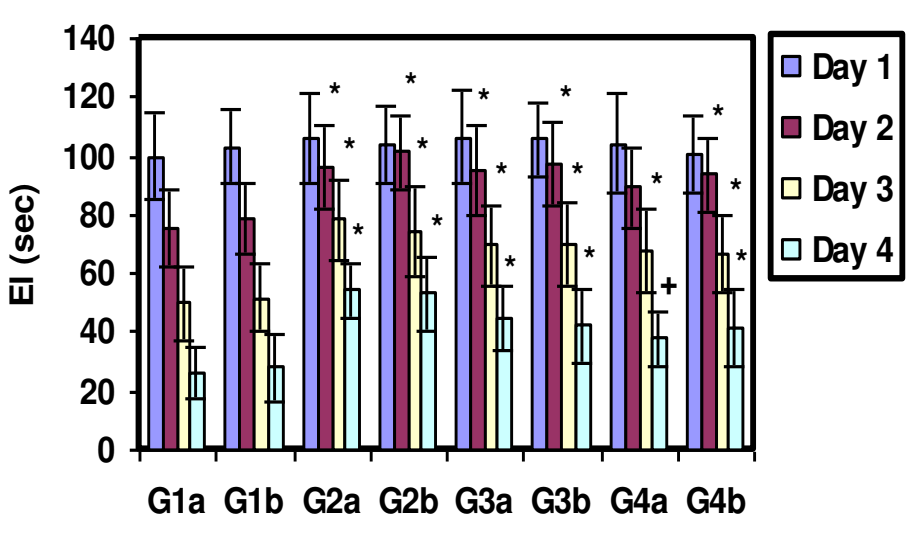

Groups

Fig. (1): Effect of 8 weeks exposure to different isoflurane concentrations on mean escape latency (EL) in seconds using Morris water maze $* \mathrm{P}<0.05$ as compared to control $+\mathrm{P}<0.05$ as compared to $\mathrm{G} 2 \mathrm{a}$

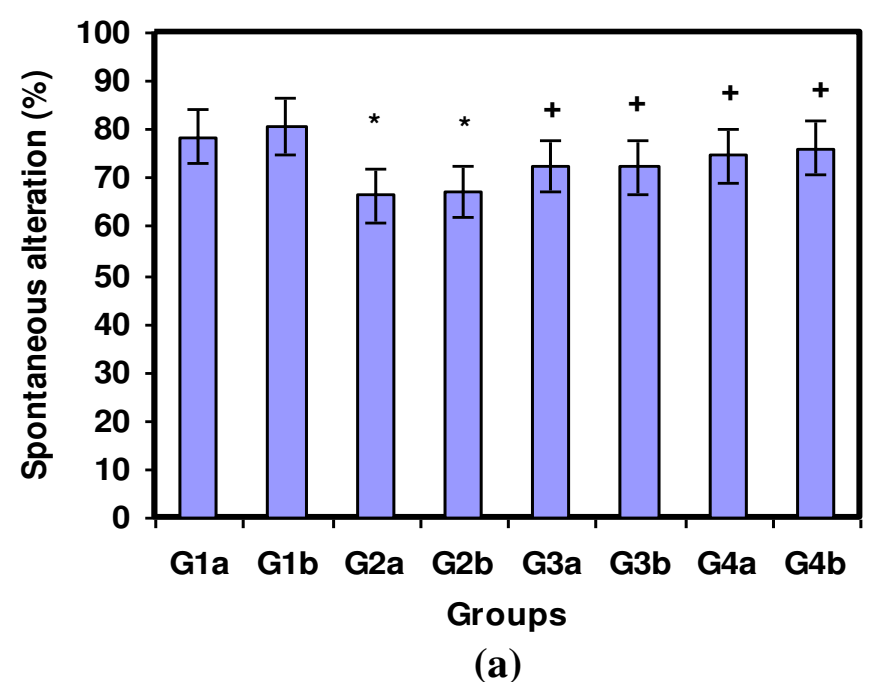

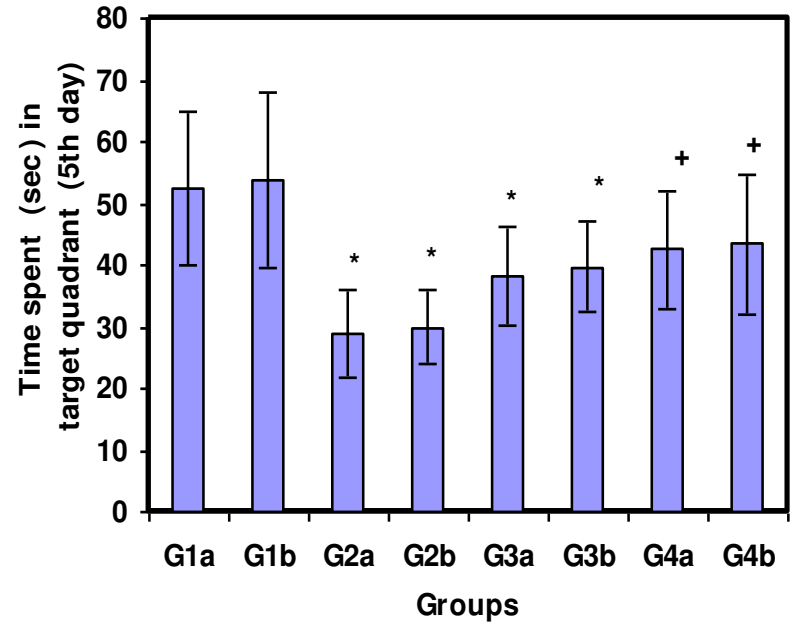

Fig: (2) Effect of 8weeks exposure to different isoflurane concentrations on time spent in target quadrant using Morris water maze $* \mathrm{P}<0.05$ as compared to control.

$\square$ Lat. start arm $\square$ Lat. choice arm

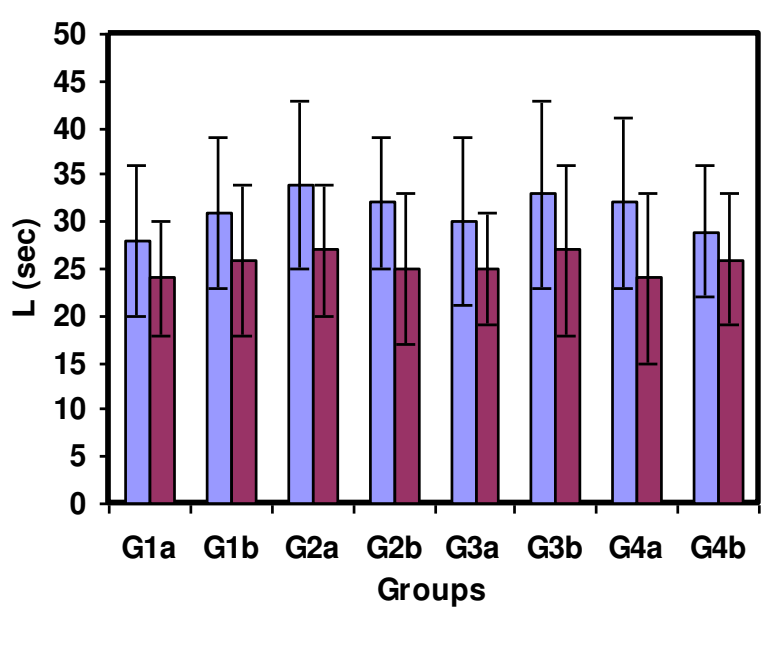

(b) $+\mathrm{P}<0.05$ as compared to $\mathrm{G} 2$.

Figure (3a,b): Effect of 8weeks exposure to different isoflurane concentrations on non spatial working memory on the T maze

$* P<0.05$ as compared to control

$+P<0.05$ as compared to $\mathrm{G} 2$


Groups



b

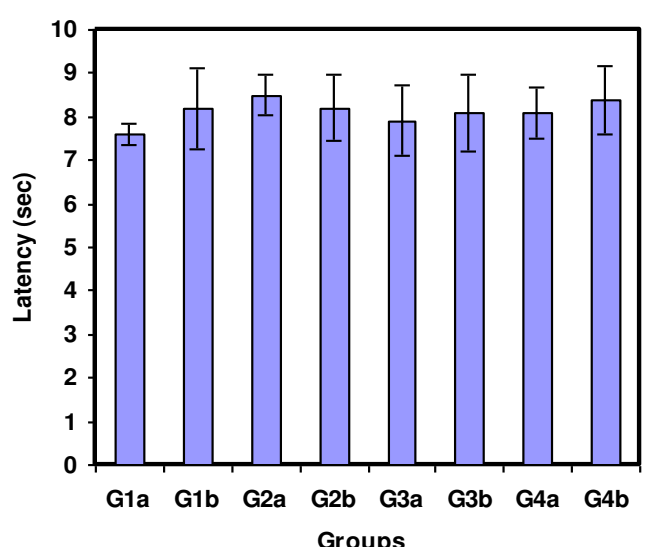

d

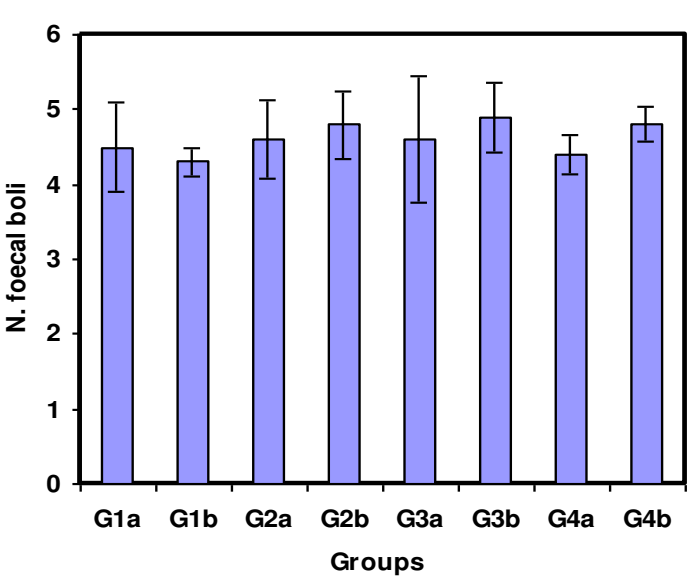

e

Fig. (4a,b.c,d,e): Effect of 8weeks exposure to different trace isoflurane concentrations on exploratory behavior parameters in open field test

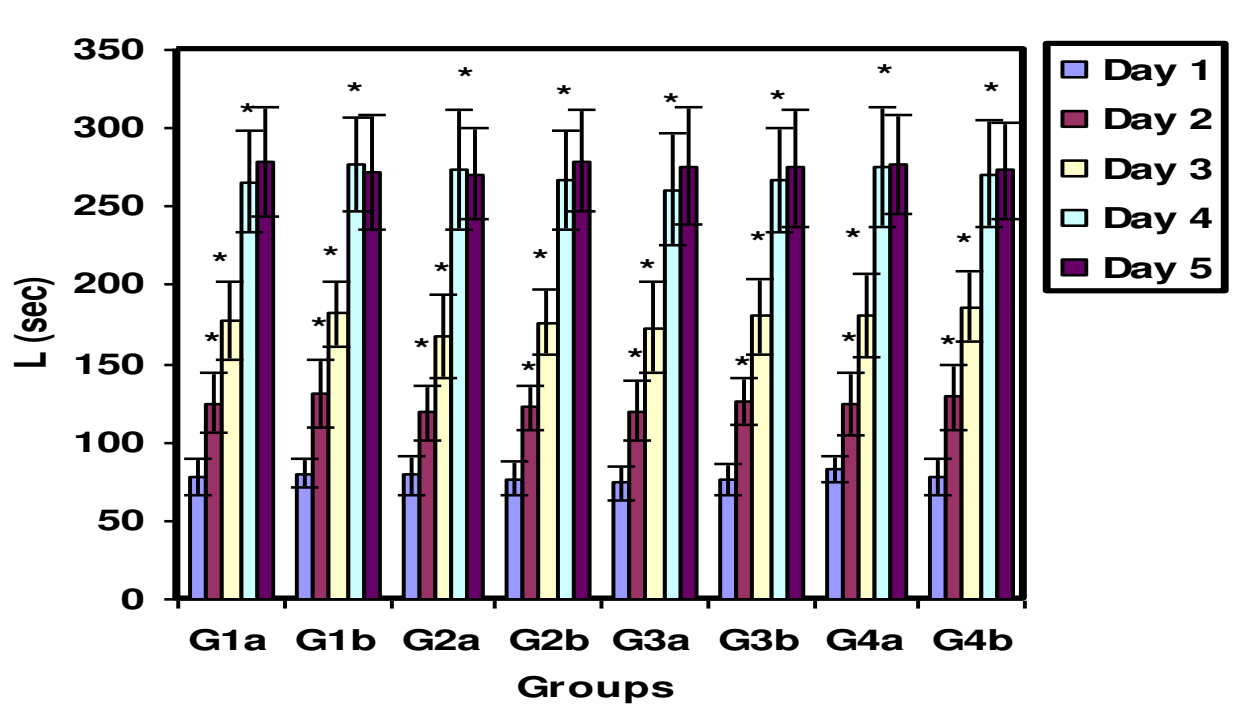

Fig: (5) Effect of 8weeks exposure to different isoflurane concentrations on latency (L) (seconds) to stay on an accelerated rotarod in mice $* P<0.05$ as compared to previous day

Conclusion: Chronic exposure to trace concentrations of isoflurane could affect some behaviors while leaving others intact. This provides an evidence of neurotoxicity of isoflurane on some brain functions in concentration bellow the upper limit according to most countries e.g. England. More and more studies should be done to evaluate these agents and provide evidenced guide lines and exposure limits that could be accepted worldwide.

\section{REFERENCES}

Cao Y, Ni C, Li Z, Li L, Liu Y, Wang C, Zhong Y, Cui D, Guo X (2015): Isoflurane anesthesia results in reversible ultrastructure and occludin tight junction protein expression changes in hippocampal blood-brain barrier in aged rats. Neurosci Lett; 587:51-6.

Tankó Béla, Levente Molnár, Béla Fülesdi, Csilla Molnár (2014): Occupational Hazards of Halogenated Volatile Anesthetics and theirPrevention: Review of the Literature. J Anesth Clin Res; 5:426.

Yang C, Zhu B, Ding J, Wang ZG (2014): Isoflurane anesthesia aggravates cognitive impairment in streptozotocin-induced diabetic rats. Int J Clin Exp Med; 7(4):903-10. 